\title{
Assessment of physicochemical characteristics, thermal stability and release profile of ascorbic acid microcapsules obtained by complex coacervation
}

\author{
Michele Cristina Rodrigues da Cruz \\ Federal University of Paraná \\ João Luiz Andreotti Dagostin \\ Federal University of Paraná \\ Camila Augusto Perussello \\ Technological University Dublin, camila.perussello@tudublin.ie
}

See next page for additional authors

Follow this and additional works at: https://arrow.tudublin.ie/ehsiart

Part of the Environmental Engineering Commons, Food Chemistry Commons, and the Medicine and Health Sciences Commons

\section{Recommended Citation}

Michele Cristina Rodrigues da Cruz, João Luiz Andreotti Dagostin, Camila Augusto Perussello, Maria Lúcia Masson, Assessment of physicochemical characteristics, thermal stability and release profile of ascorbic acid microcapsules obtained by complex coacervation, Food Hydrocolloids, Volume 87, 2019, Pages 71-82, ISSN 0268-005X, DOI: 10.1016/j.foodhyd.2018.07.043.

This Article is brought to you for free and open access by the ESHI Publications at ARROW@TU Dublin. It has been accepted for inclusion in Articles by an authorized administrator of ARROW@TU Dublin. For more information, please contact arrow.admin@tudublin.ie, aisling.coyne@tudublin.ie,gerard.connolly@tudublin.ie. Funder: CAPES (Coordination for the Improvement of Higher Education Personnel)

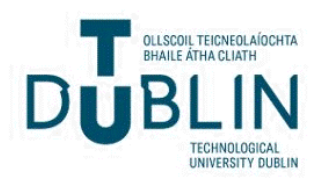




\section{Authors}

Michele Cristina Rodrigues da Cruz, João Luiz Andreotti Dagostin, Camila Augusto Perussello, and Maria Lúcia Masson 


\title{
Assessment of physicochemical characteristics, thermal stability and release profile of ascorbic acid microcapsules obtained by complex coacervation
}

\author{
Michele Cristina Rodrigues da Cruz ${ }^{\mathrm{a}, *}$, João Luiz Andreotti Dagostin ${ }^{\mathrm{a}}$, \\ Camila Augusto Perussellob ${ }^{\mathrm{b}}$, Maria Lúcia Masson ${ }^{\mathrm{a}}$ \\ ${ }^{a}$ Department of Chemical Engineering, Graduate Program in Food Engineering, Federal University of Paraná, Av. Francisco Hoffmann dos Santos s.n., CEP 81530-900, \\ Curitiba, PR, Brazil \\ ${ }^{\mathbf{b}}$ Dublin Institute of Technology, Environmental Sustainability and Health Institute, Grangegorman, D07 H6K8, Dublin, Ireland
}

\section{A R T I C L E I N F O}

\section{Keywords:}

Microencapsulation

Vitamin C

Coacervation

Emulsion

Freeze-drying

\begin{abstract}
A B S T R A C T
The aim of this study was to determine the physicochemical characteristics, thermal stability and release profile of ascorbic acid (AA) microcapsules obtained by complex coacervation. Gelatin and gum arabic were used as wall materials in concentrations of $2.5,5.0$ and $7.5 \mathrm{~g} \%(\mathrm{w} / \mathrm{v})$. The coacervate microcapsules were freeze-dried and assessed for physicochemical characteristics, thermal behavior and stability during 60 days of storage. The release profile was evaluated at different $\mathrm{pH}$ values (1.1, 2.2, 5.4, 7.4, 9.6 and 12). The encapsulation efficiency ranged from 27.3 to $93.8 \%$. The microcapsules of AA presented good characteristics for application in food matrices, such as average diameter below $12.4 \mu \mathrm{m}$, low solubility and low hygroscopicity. The AA had its thermal stability significantly improved by the encapsulation process, which extends its application in the food industry. The release of AA was slower at $\mathrm{pH}$ near neutrality, with release of 97, 96 and 99\% of encapsulated AA at 240, 300 and $270 \mathrm{~min}$ at $\mathrm{pH}$ 5.4, 7.4 and 9.6, respectively. Different mathematical models were successfully fitted to the release kinetics: $\mathrm{R}^{2}>0.94$, absolute deviations $<16 \%$ and $\mathrm{RMS}$ deviations $<0.09$. A mathematical model for a two-step release was proposed, resulting in very high correlations with the experimental data observed: $\mathrm{R}^{2}>0.99$, absolute deviations $<3.5 \%$ and $\mathrm{RMS}$ deviations around 0.02 .
\end{abstract}

\section{Introduction}

Ascorbic acid (AA) has been used as an ingredient or additive in foods due to its antioxidant and reducing properties, as well as its nutritional function as a source of vitamin C. In the food industry, AA is widely applied in meat curing and inhibition of enzymatic browning of fruits and vegetables. The degradation of AA is influenced by factors such as the presence of heat, light, high $\mathrm{pH}$ values, high oxygen concentration, high water activity and reactions catalyzed by transition metal ions, such as $\mathrm{Cu}^{2+}$ and $\mathrm{Fe}^{3+}$ (Fennema, Damodaran, \& Parkin, 2010). In aqueous solutions and in foods, their stability is directly related to the storage conditions and composition of the solution or matrix. A variety of methods has been proposed in order to increase the AA's shelf-life, including encapsulation. Encapsulation is defined as a process in which small particles or droplets (the active material) are surrounded by a coating with the main purpose of protecting them from adverse conditions of the medium, such as light, moisture, oxygen and interaction with other compounds, in addition to providing controlled release of the active compound (Abbas, Wei, Hayat, \& Xiaoming, 2012;
Fereidoon Shahidi \& Xiao-Qing Han, 1993; Gharsallaoui, Roudaut, Chambin, Voilley, \& Saurel, 2007; Gibbs, Kermasha, Alli, \& Mulligan, 1999).

Several methods of microencapsulation may be employed to improve the stability of AA, such as spray drying (Alvim, Stein, Koury, Dantas, \& Cruz, 2016; Desai \& Park, 2005; Trindade \& Grosso, 2000), spray congealing (Matos-Jr, Di Sabatino, Passerini, Favaro-Trindade, \& Albertini, 2015), microfluidic technique (Comunian, Abbaspourrad, Favaro-Trindade, \& Weitz, 2014), solvent evaporation (Uddin, Hawlader, \& Zhu, 2001), spray chilling (Sartori, Consoli, Hubinger, \& Menegalli, 2015) and the complex coacervation (Comunian et al., 2013). Coacervation is the separation of one or more hydrocolloids from an initial solution followed by deposition of the coacervate phase around an active ingredient suspended or emulsified in the reaction medium (Doublier, Garnier, Renard, \& Sanchez, 2000; Nori et al., 2011). Complex coacervation is an alternative encapsulation method for sensitive and unstable compounds, which produces a true capsule, completely protecting the active material within the wall material. The capsules produced by complex coacervation are insoluble in water,

\footnotetext{
* Corresponding author.

E-mail address: michelercruz@yahoo.com.br (M.C. Rodrigues da Cruz).
} 
resistant to high temperatures and have favorable characteristics for controlled release (Dong et al., 2011).

Some studies have been carried out with the aim of overcoming the problems related to stability and accordingly to facilitate the application of AA in food matrices. Alvim, Souza, Koury, Jurt, and Dantas (2013) produced AA microcapsules by spray-drying and by spray-chilling. The characteristics of the microparticles were compared when added in the production of biscuits. Gum arabic was used as wall material for the spray-drying, and stearic acid and hydrogenated vegetable fat for the spray-chilling. Uddin et al. (2001) encapsulated AA using different techniques, such as melt dispersion, solvent dispersion, and spray-drying. Matos-Jr et al. (2015) used spray-congealing with hydrogenated palm oil and glycerol monostearate as wall materials to encapsulate AA. Pierucci, Andrade, Baptista, Volpato, and Rocha-Leão (2006) encapsulated AA by spray-drying using concentrated pea protein as wall material. Comunian et al. (2013) used complex coacervation to encapsulate AA with gum arabic and gelatin as wall materials. Although all these studies have shown that encapsulation increases the stability of AA when compared to free AA, it is necessary to study the behavior of the microcapsules against conditions that affect the stability of the active material.

The aim of this study was to assess the physicochemical characteristics, thermal stability and release profile of AA microcapsules obtained by complex coacervation.

\section{Material and methods}

\subsection{Material}

Pure ascorbic acid (AA) (Biotec, Pinhais, Brazil) was used as the active ingredient, while the wall materials were food grade bovine gelatin type B (Gelita South America, Mococa, Brazil) and arabic gum (Biotec, Pinhais, Brazil). For the production of the simple emulsion, corn oil (Cargill, Mairinque, Brazil) and the surfactant polyglycerol polyricinoleate (PGPR 90) (SGS Agricultura e Industria Ltda, Ponta Grossa, Brazil) were used.

\subsection{Methods}

\subsubsection{Preparation of microcapsules}

The production of the microcapsules followed the method described by Comunian et al. (2013), with some modifications. The simple W/O emulsion was prepared using a $30 \%(\mathrm{w} / \mathrm{w})$ solution of AA and corn oil at a 1:1 mass ratio ( $1 \mathrm{~g}$ of AA solution: $1 \mathrm{~g}$ of oil), and the lipophilic surfactant polyglycerol polyricinoleate (PGPR 90 ) at a concentration of $0.8 \%(\mathrm{w} / \mathrm{w})$ in relation to the total mass of the emulsion. The formulation of the simple emulsion was established according to preliminary trials (results not shown), when the AA:oil proportion, time and homogenization velocity were optimized.

In order to form a simple $\mathrm{W} / \mathrm{O}$ emulsion, the blend was homogenized with a high performance homogenizer (Ultra-Turrax ${ }^{\oplus} \mathrm{T}-25$, Ika, Germany) at 22,000 rpm for $4 \mathrm{~min}$. This emulsion was considered the core and used in the calculations of the wall:core ratios. The simple W/ $\mathrm{O}$ emulsions were emulsified with gelatin solutions at concentrations of $2.5,5.0$ and $7.5 \mathrm{~g} \%(\mathrm{w} / \mathrm{v})$ at $14,000 \mathrm{rpm}$ for $3 \mathrm{~min}$ to obtain the double $\mathrm{W} / \mathrm{O} / \mathrm{W}$ emulsions. Gum arabic solutions at concentrations of 2.5, 5.0 and $7.5 \mathrm{~g} \%(\mathrm{w} / \mathrm{v})$ were slowly added to the double emulsions under constant magnetic stirring at $45^{\circ} \mathrm{C}$ for $5 \mathrm{~min}$. The $\mathrm{pH}$ was adjusted to 4.4 by addition of $\mathrm{NaOH}(1 \mathrm{~mol} / \mathrm{L})$ to promote the complex coacervation. This $\mathrm{pH}$ was chosen based on preliminary tests in which liquidliquid phase separation occurred resulting in a limpid supernatant. The solution was slowly cooled to $10^{\circ} \mathrm{C}$ in an ice bath, and the coacervate material was stored for $24 \mathrm{~h}$ at $7^{\circ} \mathrm{C}$ to promote phase separation. After $24 \mathrm{~h}$, the water was discarded and the samples were centrifuged at $3600 \mathrm{rpm}$ for $15 \mathrm{~min}$. The coacervates were transferred to vials coated with aluminum foil and then were frozen $\left(-18^{\circ} \mathrm{C}\right)$ for $24 \mathrm{~h}$ and freeze-
Table 1

Encapsulation efficiency of the microparticles produced by complex coacervation.

\begin{tabular}{lllll}
\hline Sample & $\begin{array}{l}\text { Wall concentration g\% } \\
(\mathrm{w} / \mathrm{v})^{\mathrm{a}}\end{array}$ & ${\text { Core }(\%)^{\mathrm{b}}}^{\mathrm{W}}$ & $\begin{array}{l}\text { Wall:core } \\
(\mathrm{w} / \mathrm{w})\end{array}$ & EE (\%) \\
\hline S1 & $2.5(-1)^{\mathrm{c}}$ & $25(-1)$ & $1: 0.25$ & $49.0^{\mathrm{e}} \pm 4.40$ \\
S2 & $2.5(-1)$ & $50(0)$ & $1: 0.5$ & $55.1^{\mathrm{de}} \pm 2.98$ \\
S3 & $2.5(-1)$ & $75(+1)$ & $1: 0.75$ & $56.8^{\mathrm{d}} \pm 2.55$ \\
S4 & $5.0(0)$ & $25(-1)$ & $1: 0.25$ & $27.3^{\mathrm{f}} \pm 4.46$ \\
S5 & $5.0(0)$ & $50(0)$ & $1: 0.5$ & $67.5^{\mathrm{c}} \pm 1.16$ \\
S6 & $5.0(0)$ & $75(+1)$ & $1: 0.75$ & $78.4^{\mathrm{b}} \pm 2.85$ \\
S7 & $7.5(+1)$ & $25(-1)$ & $1: 0.25$ & $60.1^{\mathrm{d}} \pm 3.02$ \\
S8 & $7.5(+1)$ & $50(0)$ & $1: 0.5$ & $93.8^{\mathrm{a}} \pm 2.23$ \\
S9 & $7.5(+1)$ & $75(+1)$ & $1: 0.75$ & $56.3^{\mathrm{d}} \pm 2.29$ \\
\hline
\end{tabular}

a The ratio of gelatin:gum arabic was fixed at 1:1.

$\mathrm{b}$ Percentage of simple emulsion (core) in relation to the total amount of polymers $(\mathrm{w} / \mathrm{w})$

c The numbers in parentheses represent the coded variables of experimental planning.

dried (LIOBRAS, LIOTOP model L101) at $-52{ }^{\circ} \mathrm{C}$ for $48 \mathrm{~h}$. After freezedried, the samples were added into glass vials coated with aluminum foil and stored in a desiccator.

The concentrations of the wall and core materials, the proportions between wall material and core (payload) and the proportions of emulsifier and corn oil in relation to the AA solution were based on the literature (Alvim et al., 2016; Comunian et al., 2013; Sartori et al., 2015). To select the best ratio between the core and the polymer pair, a $3^{2}$ full-factorial design coupled with response surface methodology (RSM) was applied according to Table 1.

\subsubsection{Characterization of the microcapsules}

2.2.2.1. Encapsulation efficiency (EE). The total AA amount was determined based on the methodology described by Alvim et al. (2016), with some modifications. One hundred mg of the freeze-dried microcapsules were completely melted in oxalic acid solution $(0.03 \%)$ at $40{ }^{\circ} \mathrm{C}$ for $5 \mathrm{~min}$. The resulting solution was transferred to a $100 \mathrm{~mL}$ volumetric flask. After preparation of the samples, the AA content present in the solution was determined according to the AOAC 967.21 (2010) method, with the modifications described by Benassi and Antunes (1988). The encapsulation efficiency was calculated by subtracting the amount of superficial ascorbic acid $\left(\mathrm{AA}_{\text {superficial }}\right)$ in the total ascorbic acid $\left(\mathrm{AA}_{\text {total }}\right)$ found in the sample, as shown in Equation (1):

$E E(\%)=\frac{A A_{\text {total }}-A A_{\text {superficial }}}{A A_{\text {total }}} \times 100$

The amount of superficial AA was determined according to the methodology described by Ribeiro, Arellano, and Grosso (2012), with some adaptations. One hundread $\mathrm{mg}$ of sample and $10 \mathrm{ml}$ of Tween 80 surfactant solution $(0.1 \%)$ were added in $125 \mathrm{ml}$ of residues and stirred at $100 \mathrm{rpm}$ for $5 \mathrm{~min}$ in an orbital shaking incubatorIn summary, $100 \mathrm{mg}$ of sample and $10 \mathrm{~mL}$ of Tween $80(0.1 \%)$ surfactant solution were added into $125 \mathrm{~mL}$ erlermeyers and shaken at $100 \mathrm{rpm}$ for $5 \mathrm{~min}$ in an incubator with orbital shaking. The suspension was then filtered on filter paper and the amount of AA in the filtrate was determined according to the AOAC 967.21 (2010) method.

2.2.2.2. Mean diameter and morphology. The mean diameter of the freeze-dried microcapsules was determined by the AxioVision LE Observer D1 (Carl Zeiss Group, Aalen, Jena, Germany) inverted optical microscope coupled to an AxioCam MR3 camera and connected to a computer. The images obtained by the AxioVision SE64 software (Carl Zeiss Microscopy, Tornwood, New York, United States) were used to calculate the mean diameter of the particle with the aid of ImageJ free software. The diameter of 150 microparticles from each different 
formulation was measured.

The morphology of the microcapsules was assessed by a scanning electron microscope (SEM) (Vega3 LMU, Tescan Orsay Holding, Brno, Czech Republic), operating in the secondary electron mode with a $15 \mathrm{kV}$ acceleration voltage. The microscope has a resolution of $3 \mathrm{~nm}$ and controlled pressure between 3 and $500 \mathrm{~Pa}$. For the SEM observations, freeze-dried microcapsules were fixed in metallic adhesive tapes adhered in metallic stubs. The stubs were covered by a thin layer of gold using an evaporator (Balzer SCD50 - Lichtenstein, Austria) set for $180 \mathrm{~s}$ at $40 \mathrm{~mA}$.

2.2.2.3. Water activity (aw) and moisture content. The water activity was assessed by direct reading with a hygrometer (Aqualab, Pullman, United States). The moisture content (expressed in wet basis) was determined by gravimetric analysis in an oven set at $105^{\circ} \mathrm{C}$ until reaching a constant weight AOAC 967.21 (2010).

2.2.2.4. Solubility and hygroscopicity. The microcapsules solubility was determined following the procedure described by Cano-Chauca, Stringheta, Ramos, and Cal-Vidal (2005), with some modifications. A sample of $1 \mathrm{~g}$ was added to $100 \mathrm{~mL}$ of distilled water at $40^{\circ} \mathrm{C}$ and stirred for $5 \mathrm{~min}$ on a magnetic stirrer. The solution was filtered using filter paper and a $20 \mathrm{~mL}$ aliquot of the filtrate was transferred to a previously weighed Petri dish, which was then heated in an oven at $105^{\circ} \mathrm{C}$ for $5 \mathrm{~h}$. The percentage solubilized was calculated by mass difference.

The hygroscopicity was determined according to the methodology described by Cai and Corke (2000) about $0.2 \mathrm{~g}$ of the sample were distributed in Petri dishes and placed in a dessicator containing a saturated solution of $\mathrm{CaCl}_{2}$, which corresponds to a relative humidity of $75 \%$ at $25{ }^{\circ} \mathrm{C}$. After 1 week, the samples were weighed and the hygroscopicity was expressed as $\mathrm{g}$ of water absorbed/100 $\mathrm{g}$ of sample.

2.2.2.5. Thermogravimetric analysis. The thermogravimetric analyses were performed with the objective of evaluating the mass variation of the active and wall material as a function of temperature. The analyses were carried out in a TGA equipment (PerkinElmer, model 4000, USA) under a nitrogen atmosphere, with flow rate of $50 \mathrm{~mL} \mathrm{~min}^{-1}$, heating rate of $10^{\circ} \mathrm{C} \cdot \mathrm{min}^{-1}$, and temperature range from 30 to $800^{\circ} \mathrm{C}$.

2.2.2.6. Spectroscopic characterization. The spectroscopic characterization of the wall materials (gum arabic and gelatin), pure AA and freeze-dried microcapsules related to sample S8 (the one that presented the best encapsulation efficiency) were performed by means of Fourier transform infrared (FTIR) spectroscopy on a Vertex 70 equipment (Bruker, USA) in the range of 4000 to $600 \mathrm{~cm}^{-1}$.

2.2.2.7. Stability of $A A$ microcapsules. The encapsulated material was stored in the presence of oxygen and protected from light at $20 \pm 2{ }^{\circ} \mathrm{C}$ in glass vials, which were kept in a desiccator for 60 days. The analyses were carried out in triplicate at 0, 15, 30, 45 and 60 days after the encapsulation process. Ascorbic acid in its free form was submitted to the same storage conditions and used as control sample. The determination of $\mathrm{AA}$ in the samples was performed using the methodology of AOAC 967.21 (2010) modified by Benassi and Antunes (1988).

2.2.2.8. Release profile. The release profile of the AA microcapsules of sample $\mathrm{S} 8$ was determined at a range of $\mathrm{pH}$ values. The $\mathrm{pH}$ values of the buffer solutions used were 1.1, 2.2, 5.4, 7.4, 9.6 and 12. A hundred mg of freeze-dried microcapsules were added into centrifuge tubes containing $10 \mathrm{~mL}$ of the buffer solution according to the $\mathrm{pH}$ chosen. Microcapsules and solutions remained in contact for $5 \mathrm{~h}$, during which $1 \mathrm{~mL}$ aliquots were taken every $15 \mathrm{~min}$ in the first hour and every 30 min afterwards. The amount of AA was determined for each aliquot according to the AOAC 967.21 (2010) modified by Benassi and Antunes (1988).
2.2.2.9. Mathematical modeling of AA release. Five different mathematical models were evaluated in the process of data fitting: three of them derived from the rate law and the other two consist of empirical models proposed by the authors. The rate law equation is given by

$r=\frac{d C}{d t}=k(\Delta C)^{n}=k\left(C_{\infty}-C\right)^{n}$

where $r$ is the reaction rate (mg.L $\left.\mathrm{L}^{-1} \mathrm{~min}^{-1}\right), k$ is the release rate constant $\left(\mathrm{min}^{-1}\right), \mathrm{C}$ and $C_{\infty}$ are the concentration of active component at a given time $(t, \mathrm{~min})$ and at equilibrium $\left(\mathrm{g} \mathrm{AA} \mathrm{g}{ }^{-1}\right.$ extractive medium), respectively, and $n$ is the order of the equation. For all trials in the very beginning of the process $(t=0)$ the concentration of active component in the medium was considered as $C=0$, and thus omitted after integration.

2.2.2.9.1. Zero order model. For $n=0$, Equation (2) is integrated to a linear algebraic solution:

$C=k t$

2.2.2.9.2. First order model. When $n=1$ the general equation of the rate law (Equation (2)) can be integrated and rearranged to the following form

$C=C_{\infty}\left(1-e^{-k t}\right)$

2.2.2.9.3. Second order model. Equation (2) can be solved analytically for $n=2$ and rearranged to obtain

$C=\frac{t}{\frac{1}{k C_{\infty}^{2}}+\frac{t}{C_{\infty}}}$

2.2.2.9.4. Proposed models. Both models proposed for describing the kinetics of release of active components from microcapsules share similarities with the first order rate law equation. The first model proposed differs from it in three characteristics: i) time $(t)$ is divided by a weight parameter $\left(w_{1}\right)$, i.e., a constant that balances its size; ii) the constant $k_{1}$ (former $k$ ) now gives power as an exponent of $t / w_{1}$; and iii) a constant $a$ was added, which has the same mathematical purpose as that of $C_{\infty}$, indicating the equilibrium for the curve evaluated. The constant $k_{1}$ can only be compared between different data sets (kinetics curves) if an equal value in the weight parameter $\left(w_{1}\right)$ can be applied. The first model proposed (PM1) is given by

$C=a\left(1-e^{-\left(\frac{t}{w_{1}}\right)^{k_{1}}}\right)$

where $a, w_{1}$ and $k_{1}$ are constants. The second model proposed (PM2, Equation (7)) basically comprises the sum of two expressions of PM1 (Equation (6)). It was built to achieve a better fit to two-step release profiles. More uncommon than regular exponential curves, these release kinetics appear as double sigmoidal shapes, which are not usually modeled.

$C=a\left(1-e^{-\left(\frac{t}{w_{1}}\right)^{k_{1}}}\right)+b\left(1-e^{-\left(\frac{t}{w_{2}}\right)^{k_{2}}}\right)$

where $b, w_{2}$ and $k_{2}$ are constants. For this equation the final concentration at equilibrium may be predicted as

$C_{\infty}=a+b$

The kinetic parameters for all models were obtained by minimizing the mean square errors between experimental and calculated data using the Levenberg-Marquardt optimization method. The parameter estimation approach for PM2 is described in the Results and Discussion section. Calculations of the average absolute relative deviation (AARD, Eq. (9)), and the root mean square error (RMSE, Eq. (10)) were performed in order to assess the goodness of fit of the mathematical models. 
$A A R D=\frac{1}{n} \sum_{i=1}^{n}\left|\frac{C_{\text {exp }}-C_{\text {pred }}}{C_{\exp }}\right|_{i} \times 100$

$R M S E=\sqrt{\sum_{i=1}^{n} \frac{\left(C_{\text {exp }}-C_{\text {pred }}\right)^{2}}{n}}$

where $n$ is the number of experimental points ( $t=0$ was not included in the calculations), and $C_{\text {exp }}$ and $C_{\text {pred }}$ are the experimental and predicted data of active compound concentration in the release medium, respectively.

2.2.2.10. Statistical analysis. The results obtained from the analytical determinations were submitted to analysis of variance (ANOVA). When the results showed significant differences among the means, they were compared by the Tukey's post-hoc test at $5 \%$ level of significance $(\mathrm{p} \leq 0.05)$.

\section{Results and discussion}

\subsection{Encapsulation efficiency}

Table 1 presents the EE of the microcapsules, which ranged from $27.3 \%$ (S4) to $93.8 \%$ (S8). The wall material concentration and core percentage had both a strong influence on the results. An increase in the core percentage led to higher EEs using $2.5 \mathrm{~g} \%(\mathrm{w} / \mathrm{v})$ and $5.0 \mathrm{~g} \%(\mathrm{w} / \mathrm{v})$ of wall material, however an opposite trend occurred for a higher wall concentration $(7.5 \mathrm{~g} \%(\mathrm{w} / \mathrm{v}))$. Also, not all particles containing higher wall concentrations showed higher EE for the same core percentage (as comparing samples S1 and S4, for instance). Thus, the increase in the wall material concentration is not always sufficient to ensure a proper encapsulation of the core.

There were no significant differences of EE between samples using a wall:core ratios of 1:0.5 (S2) and 1:0.75 (S3). For both samples with $2.5 \mathrm{~g} \%(\mathrm{w} / \mathrm{v})$ of wall concentration, the increase in core percentage led to a lower encapsulation efficiency. These low EEs confirm the hypothesis that an insufficient amount of wall materials was available to cover the entire core, resulting in a high free core concentration, i.e. a high amount of core that was not encapsulated and hence was lost during the encapsulation process. Regarding samples S5, S6 and S8, they showed high EE, which can be explained by the higher concentrations of wall material $(5.0$ and $7.5 \mathrm{~g} \%(\mathrm{w} / \mathrm{v}))$. Thus, these concentrations were sufficient to cover a greater amount of core, which is extremely important to ensure that the active material is imprisoned inside the capsule and does not lose functionality. However, even with the increase of the wall material concentration, samples S1 and S4 showed the lowest values of EE. These results can be ascribed to the increased viscosity caused by the high polymer concentration, which probably interferes with the microcapsules formation as a result of the lower mobility of the macromolecules and the consequent increase in the competition for solvent molecules, as described by Thies (1995). Another factor to be considered is that some negatively charged carboxyl groups of gum arabic were not complexed with gelatin molecules, causing ionic imbalance and decreasing the encapsulation yield.

In several other papers, higher concentrations of the wall material increased the EE, following a linear trend. This study presented a nonlinear behavior, as can be observed in samples S1 and S4. Santos, Bozza, Thomazini, and Favaro-Trindade (2015) studied the encapsulation of xylitol by complex coacervation. The EE ranged from 31.42 to $71.93 \%$, and the lowest efficiencies were found for a wall material concentration of $2.5 \mathrm{~g} \%(\mathrm{w} / \mathrm{v})$. The highest efficiency $(71.93 \%)$ was found for the wall material concentration of $7.5 \mathrm{~g} \%(\mathrm{w} / \mathrm{v})$ with $50 \%$ core, in agreement with the results obtained in this study. The same behavior was found in the encapsulation of turmeric oleosarin by complex coacervation in the work developed by Zuanon, Malacrida, and Telis (2013), where systems with a higher concentration of wall material presented higher values of encapsulation efficiency.

The encapsulation efficiency is high in most studies involving complex coacervation with hydrophobic agents. In the study carried out by Rutz, Borges, Zambiazi, da Rosa, Cleonice, \& da Silva (2016), for example, it was observed values above $95 \%$ in the encapsulation of carotenoids. Rutz et al. (2017) reached an EE of up to $99 \%$ with palm oil and Yang et al. (2014) reached up to $94 \%$ with the encapsulation of vanilla oil. The results obtained in this study were quite varied due to the high solubility of the core in water and also to the electrostatic interactions that may have been formed between the wall material and the core. However, these interactions were minimized as the solubility of AA decreased as a result of the water/oil core emulsion comprising AA and corn oil. Hydrophilic active agents, such as AA, are usually not directly encapsulated by complex coacervation, requiring an additional step for obtaining the active agent in the oil emulsion, as demonstrated in this and other studies (Comunian et al., 2013; Rocha-Selmi, Bozza, et al. 2013; Rocha-Selmi, Theodoro, et al. 2013; Santos et al., 2015).

The wall polymers concentration and the core percentage, as well as the interaction between these two variables, significantly influenced the microcapsules' EE, as shown in Fig. 1. An increase in the amount of core and the concentration of wall polymers likely results in higher encapsulation efficiencies (positive correlation coefficients of 15.92 and 14.66, respectively). However, the interaction between the two variables studied did not have a direct effect on the EE (correlation coefficient of -4.43), meaning that certain combinations of core percentage and wall concentration may result in low efficiencies.

\subsection{Mean diameter and morphology}

The mean diameter of the microcapsules is an important parameter and directs their application in food matrices as it may influence the texture of the food. Table 2 presents the results of the mean diameter of the lyophilized coacervated microcapsules for the different formulations tested.

The AA microcapsules obtained in this work exhibit diameters ranging from 7.7 to $12.4 \mu \mathrm{m}$. According to Favaro-trindade et al. (2008), microcapsules produced by complex coacervation have in fact diameters among 1 and $500 \mu \mathrm{m}$. Table 2 shows that there was a significant difference between the samples, where the percentages of wall material and core influenced the mean particle diameter. Samples S3 $(10.6 \mu \mathrm{m})$, S6 $(12.4 \mu \mathrm{m})$ and S9 $(12.3 \mu \mathrm{m})$ containing $75 \%$ core showed the highest mean diameters, while S4, S5 and S7 presented the smallest diameters (8.5, 7.7 and $9.7 \mu \mathrm{m}$, respectively). These samples were produced with wall polymer concentrations of 5.0 and $7.5 \mathrm{~g} \%(\mathrm{w} / \mathrm{v})$ and with 25 and $50 \%$ of core, which means that the increase of in wall material concentration did not result in larger diameters, as observed in other works (Rocha-Selmi et al., 2013a).

The mean diameters obtained in this study were lower than those found in other studies. Comunian et al. (2013) produced medium size AA microcapsules ranging from 51.67 to $83.82 \mu \mathrm{m}$, Rocha-Selmi et al. (2013b) encapsulated sucralose with an average size of 81.04-113.49 $\mu \mathrm{m}$ and Santos et al. (2015) produced microcapsules with diameters from 78.45 to $109.31 \mu \mathrm{m}$. All these studies used the same wall material as in the present paper. This difference in diameter can be related to the speed and time of homogenization used in the emulsions, which were higher to those of the works mentioned. Mendanha et al. (2009) used a homogenization speed of $20,000 \mathrm{rpm}$ in the encapsulation of casein hydrolyzate and obtained microcapsules between 16 and $24 \mu \mathrm{m}$ with pectin and soy protein hydrolyzate as wall materials. In addition to the speed of homogenization and the proportion of core and wall polymers, other factors may influence the particle size, such as the concentration of the polymers, the payload and the type of drying used in the process (Lamprecht, Schäfer, \& Lehr, 2000; Nakagawa, Iwamoto, Nakajima, Shono, \& Satoh, 2004).

Fig. 2A and B shows the optical microscopy images of the moist and freeze-dried coacervates, respectively. The microcapsules are spherical 


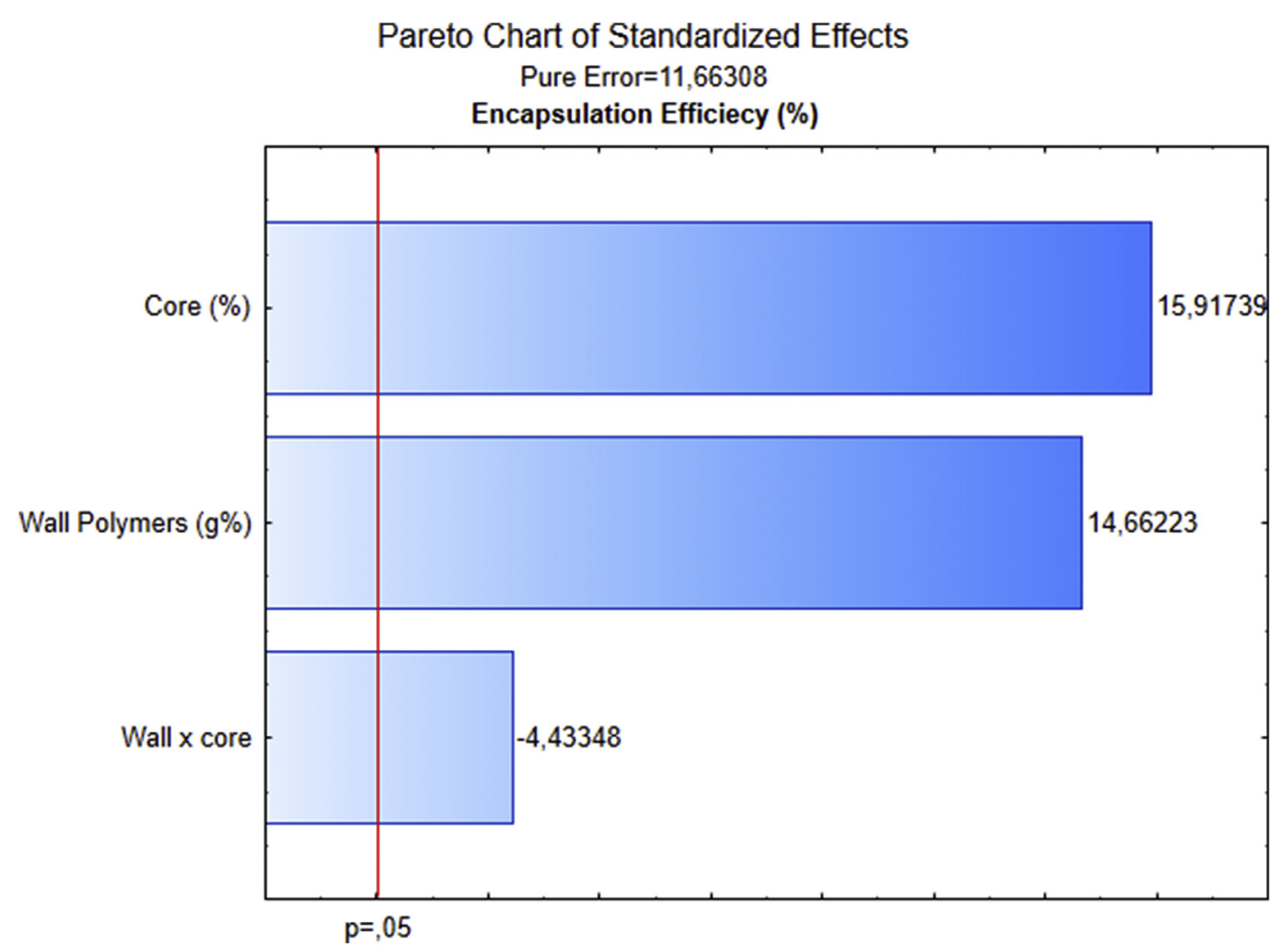

Fig. 1. Pareto chart of the effects of the process variables on encapsulation efficiency.

Table 2

Physicochemical properties of AA microcapsules produced by complex coacervation.

\begin{tabular}{|c|c|c|c|c|c|}
\hline Sample & Mean diameter $(\mu \mathrm{m})$ & Moisture (\%) & $\mathrm{aW}$ & Solubility (\%) & Hygroscopicity (g/100 g) \\
\hline S1 & $10.3^{\mathrm{bcd}} \pm 6.33$ & $12.6^{\mathrm{a}} \pm 1.65$ & $0.24^{\mathrm{c}} \pm 0.005$ & $6.9^{\mathrm{e}} \pm 0.24$ & $3.6^{\mathrm{bc}} \pm 0.27$ \\
\hline S2 & $9.8^{\mathrm{cd}} \pm 6.05$ & $2.1^{\mathrm{b}} \pm 1.65$ & $0.25^{c} \pm 0.001$ & $7.4^{\mathrm{de}} \pm 0.48$ & $3.4^{\mathrm{d}} \pm 0.46$ \\
\hline S3 & $10.6^{\mathrm{b}} \pm 7.81$ & $10.0^{\mathrm{a}} \pm 0.95$ & $0.28^{\mathrm{b}} \pm 0.007$ & $2.3^{\mathrm{f}} \pm 0.03$ & $2.6^{\mathrm{de}} \pm 0.01$ \\
\hline S4 & $8.5^{\mathrm{e}} \pm 5.39$ & $3.9^{\mathrm{b}} \pm 1.27$ & $0.18^{\mathrm{d}} \pm 0.011$ & $12.2^{c} \pm 0.13$ & $4.9^{\mathrm{ab}} \pm 0.04$ \\
\hline S5 & $7.7^{\mathrm{f}} \pm 8.19$ & $1.6^{\mathrm{b}} \pm 0.34$ & $0.23^{c} \pm 0.01$ & $14.03^{b} \pm 0.88$ & $5.1^{\mathrm{a}} \pm 0.89$ \\
\hline S6 & $12.4^{\mathrm{a}} \pm 11.35$ & $11.0^{\mathrm{a}} \pm 2.18$ & $0.30^{\mathrm{b}} \pm 0.003$ & $5.8^{\mathrm{e}} \pm 0.03$ & $1.5^{\mathrm{e}} \pm 0.02$ \\
\hline S7 & $9.7^{d} \pm 6.13$ & $2.7^{\mathrm{b}} \pm 0.37$ & $0.17^{\mathrm{d}} \pm 0.005$ & $8.6^{\mathrm{d}} \pm 0.01$ & $3.4^{\mathrm{bc}} \pm 0.32$ \\
\hline S8 & $10.3^{\mathrm{bc}} \pm 9.15$ & $1.6^{b} \pm 0.50$ & $0.24^{\mathrm{c}} \pm 0.01$ & $16.1^{\mathrm{a}} \pm 0.90$ & $2.4^{\text {de }} \pm 0.20$ \\
\hline S9 & $12.3^{\mathrm{a}} \pm 10.2$ & $3.1^{\mathrm{b}} \pm 0.56$ & $0.35^{\mathrm{a}} \pm 0.01$ & $11.2^{\mathrm{c}} \pm 0.27$ & $3.3^{\mathrm{d}} \pm 0.24$ \\
\hline
\end{tabular}

of reservoir type (Fig. 2A), where the nucleus is clearly concentrated in the central region, surrounded by a defined and continuous film of wall material. According to Dong et al. (2011), this type of capsule offers excellent characteristics when the goal is the controlled release of the active compound.

The morphology of the microcapsules of sample S8 after the freezedrying process are seen in Fig. 2C and D. Fig. 2C shows agglomerated microcapsules, which is very common in microcapsules that have undergone freeze-drying. Other authors also observed the same behavior (Alvim \& Grosso, 2010; Comunian et al., 2013; Prata \& Grosso, 2015). The scanning electric microscopy (SEM) photographs show a capsule with solid walls and no cracks, indicating that the drying process chosen for the particles was appropriate as the encapsulated material showed no damage on its surface. An undamaged surface is important to ensure greater protection and retention of the encapsulated material.

\subsection{Moisture, water activity (aw), solubility, hygroscopicity}

Table 2 shows the values obtained for moisture, water activity (aw), solubility and hygroscopicity of the coacervated and freeze-dried particles. Moisture ranged from 1.6 to $12.6 \%$, with S1, S3 and S6 showing the highest moisture content. Samples S2, S4, S5, S7, S8 and S9 presented similar behavior, but a lower moisture content than S1, S3 and S6. The aw ranged from 0.17 to 0.35 , lower values than those found by Comunian et al. (2013) for microcapsules obtained by complex coacervation in the encapsulation of AA with the same wall materials as in this study.

The solubility of freeze-dried microcapsules ranged from 2.3 to $16.1 \%$, similar to those obtained by Santos et al. (2015) for microcapsules of xylitol. Low solubility values are favorable because the low solubility is important for the stability of microcapsules in an aqueous medium and when controlled release is desired. Regarding the hygroscopicity values, they were in the range of $1.5-5.1 \mathrm{~g} / 100 \mathrm{~g}$, which provide the particles a good stability during storage. No relationship was found between the core ratio and the hygroscopicity, i.e., there was no increase in hygroscopicity with increasing core concentration (Nori et al., 2011; Silva, Favaro-Trindade, Rocha, \& Thomazini, 2012).

\subsection{Thermal analysis}

A thermogravimetric analysis was performed to evaluate the thermal behavior of the microcapsules, the polymers used as wall 

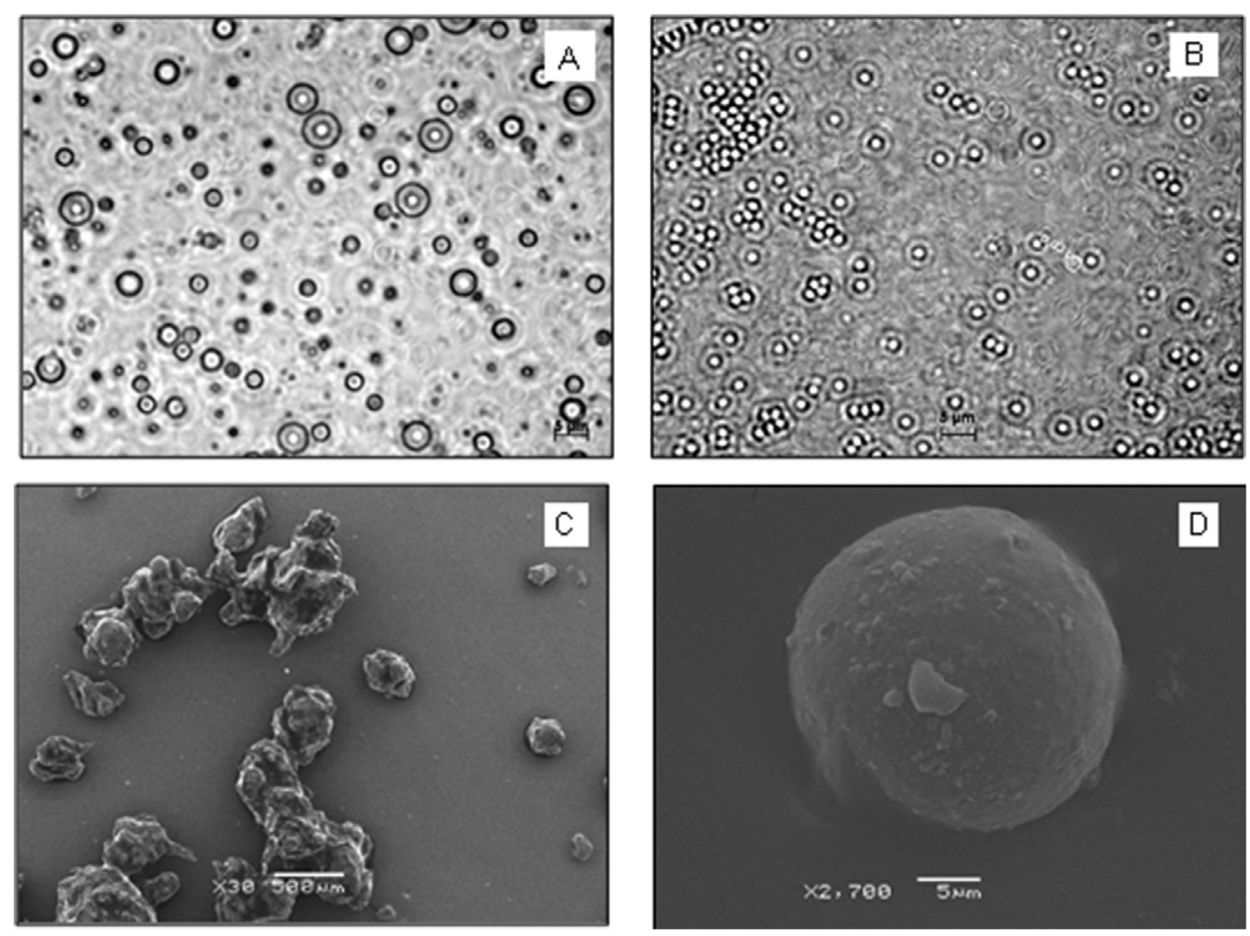

Fig. 2. Micrographs of the coacervated microcapsules: (A) sample 8 by optic microscopy ( $1600 \mathrm{x}$ ); (B) freeze-dried sample 8 by optic microscopy (1600 x); (C) freezedried sample 8 by scanning electron microscopy $(30 \mathrm{x})$ (D) freeze-dried sample 8 by scanning electron microscopy $(2700 \mathrm{x})$.
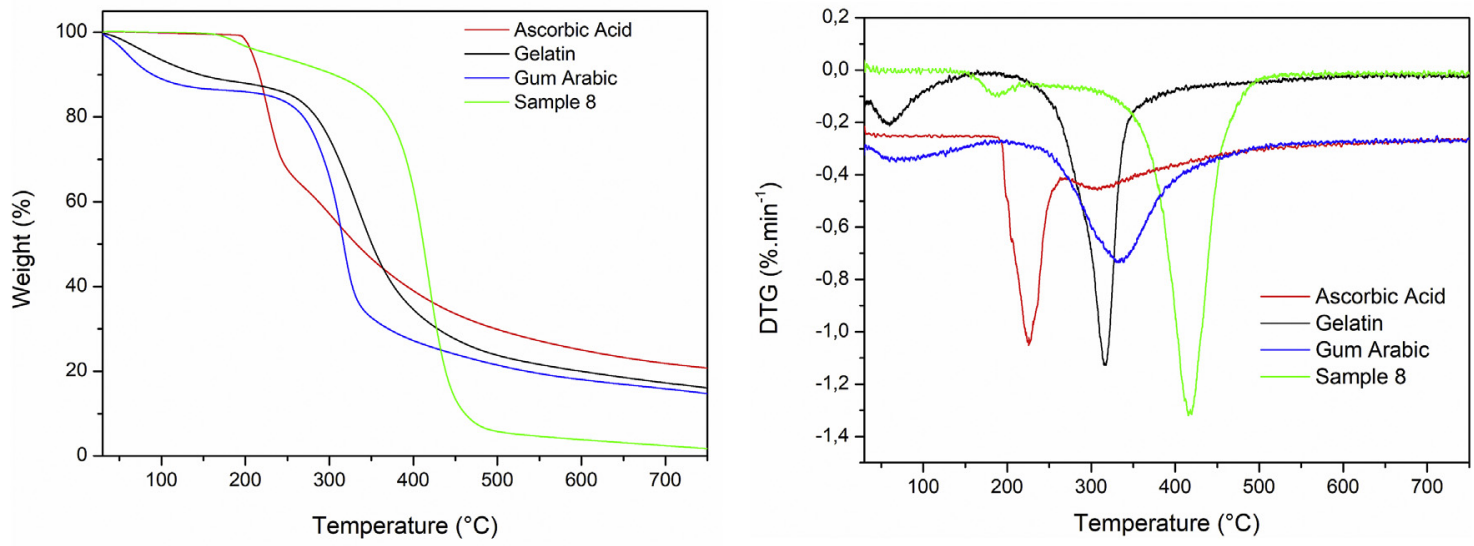

Fig. 3. Thermal behavior of pure AA, gelatin, gum arabic and sample 8 and their respective derivatives.

material, and the core. As all the samples presented a similar behavior, only the results of the sample with the highest encapsulation efficiency were presented. Fig. 3 shows the thermograms of microcapsules from sample S8, pure AA, gelatin and gum Arabic, and their respective derivatives. The peaks observed in the DTG curves identify the beginning and the end of a thermal degradation. The thermogram for the pure AA showed two thermal events, one at $193-250{ }^{\circ} \mathrm{C}$ with a related mass loss of $31.8 \%$, and another of $275-311^{\circ} \mathrm{C}$, corresponding to a mass loss of $12.4 \%$. According to Jingyan, Yuwen, Zhiyong, and Cunxin (2013), the main event related to AA decomposition occurs from 191 to $268^{\circ} \mathrm{C}$, with simultaneous loss of one molecule of $\mathrm{H}_{2} \mathrm{O}$ and one $\mathrm{CO}_{2}$ molecule. After the analysis, there was about $20 \%$ of remaining materials that could not vaporize up to $800^{\circ} \mathrm{C}$, such as ashes. The gelatin had two thermal degradation events, the first between 31 and $139^{\circ} \mathrm{C}$, corresponding to a mass loss of approximately $9 \%$, probably due to weight loss of the remaining water in the sample (Torini, Argillier, \& Zydowicz, 2005). Another event was observed from 271.8 to $391.3^{\circ} \mathrm{C}$, the temperature range where protein degradation occurs, corresponding to
$56 \%$ of weight loss. Gum arabic presented two well-defined thermal events. The first event $\left(38-90^{\circ} \mathrm{C}\right)$ with a weight loss of $8.7 \%$, and the second event $\left(286-339^{\circ} \mathrm{C}\right)$ with $52.7 \%$ weight loss, attributed to the degradation of polysaccharides.

The thermal degradation process of sample 8 presented two thermal events. The first in the range from 168 to $218^{\circ} \mathrm{C}$, with $4 \%$ mass loss. In the second event $\left(377-456{ }^{\circ} \mathrm{C}\right)$ there was a significant mass loss, about $85 \%$. The release of the core material along with the decomposition of the polysaccharide and the protein used as wall materials may have caused this high weight loss (Lv, Zhang, Zhang, Abbas, \& Karangwa, 2013). The results confirmed that the AA thermal stability was significantly improved by the encapsulation process. This increased thermal stability can be attributed to the thermal resistance of the materials used as microcapsule casing, resulting in a slower heat transfer. With the increased thermal stability of the microencapsulated $\mathrm{AA}$, there is a consequent increase in the temperature range in which the active compound may be incorporated into the food matrix without loss of its properties during processing. 

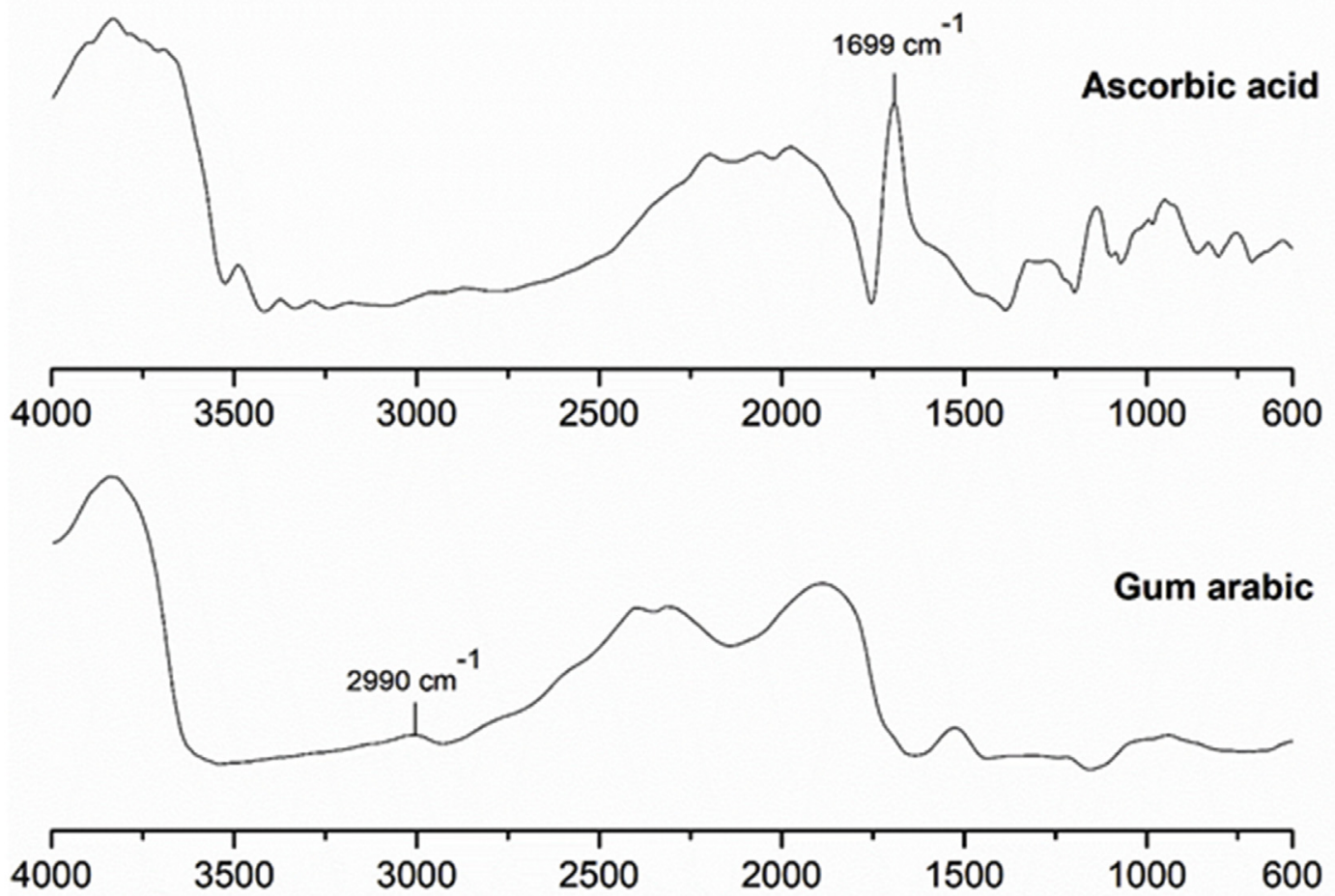

Gelatin
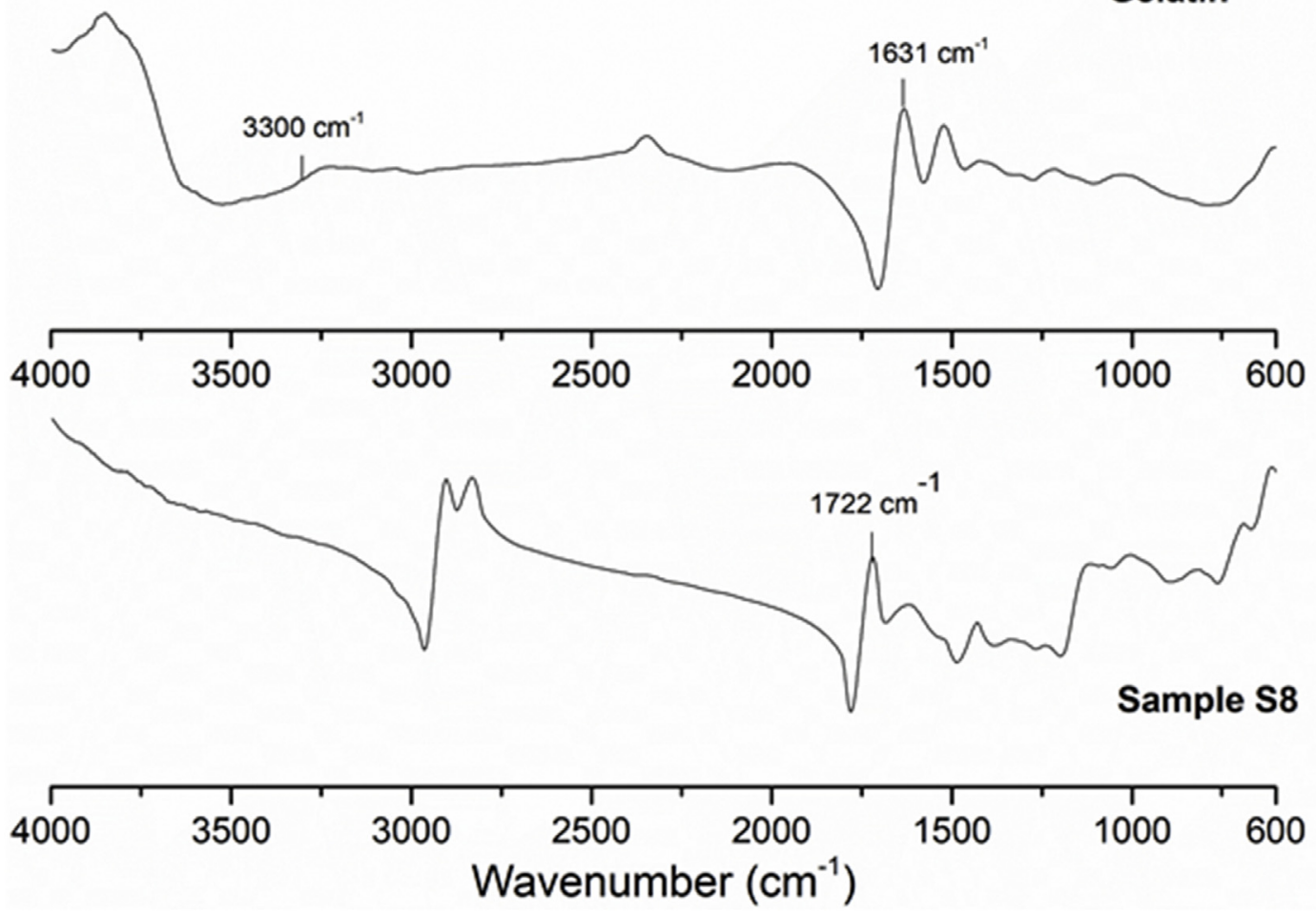

Fig. 4. Spectra obtained by FTIR for gelatin, gum arabic, pure AA and sample S8.

\subsection{Spectroscopic characterization}

The FTIR analysis can provide information about the interactions that occur between gelatin, gum arabic and AA during the complex coacervation process. The spectra obtained showed a very similar behavior, with differences only in the intensity of the peaks. Such differences are related to the concentration of the wall material and core material used in the production of the microcapsules. Therefore, we selected only sample S8 in this analysis, since it exhibits the best EE.

The spectra obtained for the wall materials, core and sample S8 are shown in Fig. 4. The pure AA sample showed peaks at 1140, 1310 and $1699 \mathrm{~cm}^{-1}$, which according to Desai and Park (2005) can be attributed to $\mathrm{C}=\mathrm{O}$ and $\mathrm{OH}$ groups in the AA molecule. The peak observed at $1699 \mathrm{~cm}^{-1}$ in the pure AA spectrum is repeated in the 
microencapsulated particles of sample S8, but with a small displacement from $1699 \mathrm{~cm}^{-1}$ to $1722 \mathrm{~cm}^{-1}$, confirming the presence of the active material.

Peaks in the $3300 \mathrm{~cm}^{-1}$ region in the gelatin spectrum are characteristic of amine groups. These peaks usually appear in basic amino acid residues such as lysine, histidine and arginine, and depending on the $\mathrm{pH}$ of the medium they may show positive charges. The peaks with a low intensity - about $2990 \mathrm{~cm}^{-1}$ in the gum arabic spectrum - are characteristic of carboxyl groups and may exhibit negative charges. Peaks in this region for gum arabic are ascribed to the protein fraction present in the molecule, that is, acidic amino acid residues such as glutamic and aspartic acid.

Other peaks can be observed in the gelatin molecule in the region of $1550-1650 \mathrm{~cm}^{-1}$. The peak at $1631 \mathrm{~cm}^{-1}$ in the gelatin spectrum refers to amide $\mathrm{I}$ and is due to the stretching at $\mathrm{C}=\mathrm{O}$ and the deformation of $\mathrm{NH}$. This wavelength may be linked to the secondary structure of proteins ( $\beta$ - sheets), which favors the interaction between biopolymers in the complex formation process (Anvari \& Chung, 2016).

\subsection{Stability of AA microcapsules}

Fig. 5 and Table S1 (in supplementary material) shows stability results for AA microcapsules during 60 days and for pure AA (control) over 15 days. The AA in solution is susceptible to oxidation, especially when exposed to factors such as light, heat, and oxygen (Fennema et al., 2010). In this work there was no temperature variation and the samples were not exposed to light, even though there was a rapid degradation of AA in its free form, as can be seen in Fig. 5.

The degradation of free AA was faster compared to the encapsulated AA: while after 15 days of storage there was only $15 \%$ of free AA available, the encapsulated samples exhibited retentions of $20.5 \%-90.3 \%$. Due to the high degradation of the pure AA, it was possible to quantify it until the 18th day, when there was only $2.5 \%$ of AA left. This rapid release behavior of free AA was also observed by Comunian et al. (2013) and Comunian et al. (2014). The instability of AA was also observed in the encapsulated samples, but with a much lower degradation rate (Fig. 5).

In general, the encapsulated samples showed a similar behavior, with a slower degradation up to 60 days of storage, except for samples S8 and S4, which presented the highest (93.8\%) and the lowest (27.3\%) stability over storage. A low encapsulation efficiency might mean there is too much uncapsulated core on the surface of the capsule, as observed in sample S4. This sample also exhibited one of the smallest mean diameters (Table 2). In fact, the smaller the size of the capsule, the greater the exposed surface of AA, resulting in lower stability. The opposite is true for the S8 sample, which showed a larger diameter, and thus a smaller exposure surface, which can explain its greater stability.

The results obtained in this work demonstrate that the encapsulation process increased significantly the stability of AA when compared to other studies. In the study carried out by Comunian et al. (2013) in the encapsulation of AA using a double emulsion followed by complex coacervation, a $60 \%$ AA retention was obtained after 30 days of storage. In another case, Rozman and Gašperlin (2007) encapsulated AA through W/O type microemulsions, obtaining only $60 \%$ AA retention in the samples stored at room temperature over 30 days. The stability obtained by both authors was lower than that obtained in the present study $(80 \% \pm 0.86 \%)$ for the same concentration of wall and core materials ( $7.5 \mathrm{~g} \%$ gelatin and gum arabic and 50\% core - sample S8). This higher stability can be attributed to the conditions of preparation of the simple emulsion, considered as core, which in this work were different from those used by Comunian et al. (2013).

\subsection{Release profile}

The study of the release profile of an active ingredient is important to understand its behavior and the mechanism by which release occurs. Tests carried out under specific conditions can provide useful information, especially regarding the food matrices this active material can be incorporated to. Sample S8 was chosen for the release profile because it exhibited the best encapsulation efficiency, which means that a smaller amount of active compound adheres to the microcapsule's surface. Fig. 6 and Table S2 (in supplementary material) show the release profile of AA microcapsules at diferent $\mathrm{pH}$ values. In general, the release of $\mathrm{AA}$ at acidic and basic $\mathrm{pH}$ values was faster than at $\mathrm{pH}$ near neutrality. Such results are important for evaluating the industrial application of the encapsulated product.

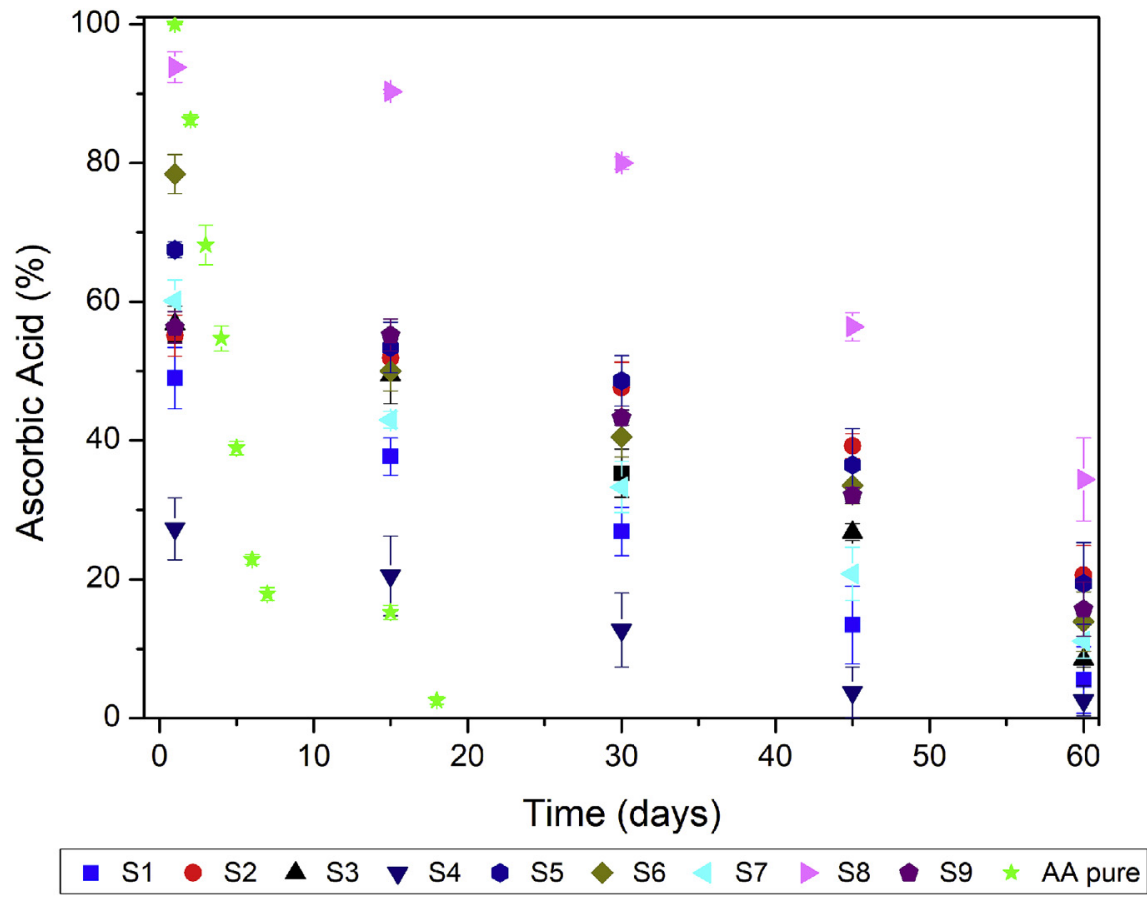

Fig. 5. Stability of pure AA and AA microcapsules for 60 days storage at $20^{\circ} \mathrm{C}$. 

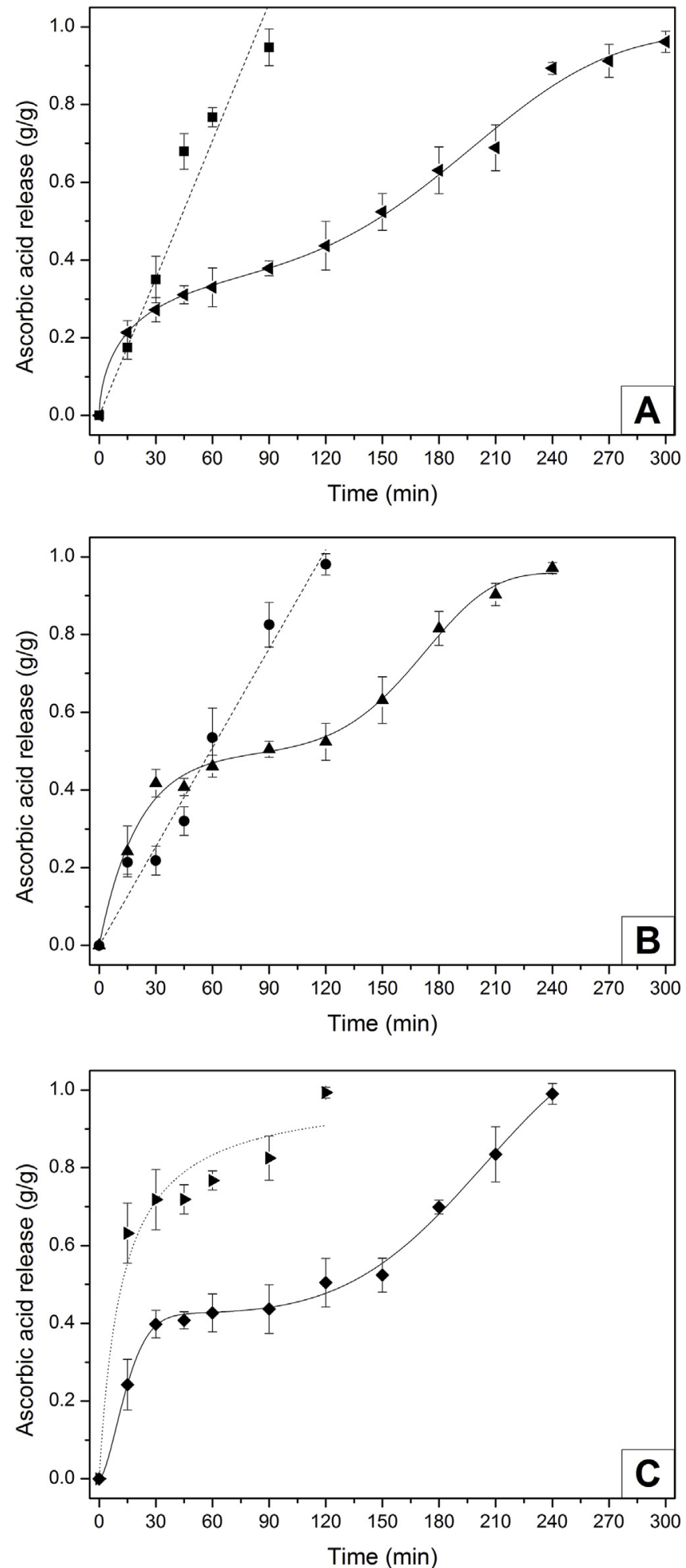

Fig. 6. Release profile of ascorbic acid from microcapsules of sample $\mathrm{S} 8$ at $\mathrm{pH}$ $1.1(\boldsymbol{\square}), 2.2(\bullet), 5.4(\boldsymbol{\Delta}), 7.6(\triangleleft), 9.6(\diamond)$, and $12.0(\boldsymbol{\nabla})$. Lines correspond to the models that best described the data sets: $0^{\text {th }}$ order ( - ), 2nd order ( $\left.\cdots \cdot\right)$ and PM2 models (-).

The microcapsules that remained in contact with a solution at $\mathrm{pH}$ 12.0 showed the fastest release: about $63 \%$ AA was released in $15 \mathrm{~min}$, as shown in Fig. 6. At 90 min of analysis, $94.69 \%$ of the AA content was released at $\mathrm{pH} 1.1$ and about $82 \%$ at $\mathrm{pH} 2.2$ and 12.0, a higher release when compared to $\mathrm{pH}$ close to neutrality (38\%). The effect of the high initial release of the active agent is known as "burst release" (Lakkis,
Table 3

Ascorbic acid release at $\mathrm{pH} 1.1$ and 2.2: Kinetic parameters and deviations calculated for the Rate Law equations.

\begin{tabular}{lllll}
\hline Model & $\mathrm{k}$ & $\mathrm{R}^{2}$ & AARD (\%) & RMSE \\
\hline pH 1.1 & & & & \\
$0^{\text {th }}$ order & $0.01178 \pm 0.00072$ & 0.9430 & 8.76 & 0.09 \\
$1^{\text {st } \text { order }}$ & $0.02136 \pm 0.00267$ & 0.9419 & 23.33 & 0.09 \\
$2^{\text {nd } \text { order }}$ & $0.03396 \pm 0.00970$ & 0.8491 & 36.22 & 0.14 \\
\hline pH 2.2 & & & & \\
\hline $0^{\text {th }}$ order & $0.00848 \pm 0.00032$ & 0.9757 & 15.36 & 0.06 \\
$1^{\text {st }}$ order & $0.01398 \pm 0.00211$ & 0.8964 & 25.09 & 0.11 \\
$2^{\text {nd }}$ order & $0.02105 \pm 0.00616$ & 0.7940 & 32.20 & 0.16 \\
\hline
\end{tabular}

For all equations $C_{\infty}$ was set as $1(100 \%$ release).

2007; Prata, Menut, Leydet, Trigo, \& Grosso, 2008). This quick release can be observed for different methods of encapsulation, encapsulation materials and also for different active agents. Alvim and Grosso (2010) microencapsulated paprika oleoresin by complex coacervation and observed a marked release in the first $15 \mathrm{~min}$ of the experiment. Yang et al. (2014) microencapsulated vanilla oil by complex coacervation and also observed a "burst" effect.

The "burst" effect observed in this sample can be ascribed to the degradation of the wall material due to the extreme $\mathrm{pH}$ conditions, such as 1.1, 2.2 and 12.0, since the high encapsulation efficiency (around 93\%) indicates a low adherence of active material to the outer surface of the microcapsules. According to Comunian and Favaro-Trindade (2016), the $\mathrm{pH}$ changes of the medium may contribute to the degradation of microcapsules produced by complex coacervation due to the alteration of the wall polymers' solubility. The microcapsules that remained in contact with solutions of pH 5.4, 7.4 and 9.6 had no significant difference in their release profile during all the $120 \mathrm{~min}$ of the analyses, whereas a release of approximately $98 \%$ of the microencapsulated AA occurred at $\mathrm{pH} 2.2$ and 12.0. Among all pH tested the microcapsules in contact with the solution $\mathrm{pH} 7.4$ showed the slowest release: about $96 \%$ AA was released after $300 \mathrm{~min}$.

The release of an active compound involves a few steps, such as absorption of the solvent by the capsule, dissolution of the wall, dissolution of the core, permeation of the core by the wall, and finally diffusion of the core by the solvent (Matalanis, Jones, \& McClements, 2011). Therefore, the wall material will determine the release mechanism of the active compound. This mechanism can be modulated by the molecular weight of the polymer, because of the larger the molecular weight, the slower the release of the encapsulated compounds (Kumari, Yadav, \& Yadav, 2010).

The study of controlled release characteristics of bioactive compounds as AA is of fundamental importance, especially when these encapsulates are added to food matrices. Microcapsules that provide controlled release are able to protect the active component from being released or degraded due to processing conditions (Belšćak-Cvitanović et al., 2011).

\subsubsection{Mathematical modeling of AA release}

Kinetic data of active components release from microcapsules usually exhibit exponential or linear trends. In most cases, the rate law for chemical reactions can be successfully applied with satisfactory prediction. For this specific case, the ascorbic acid release showed different rates according to time and $\mathrm{pH}$.

The AA release data set did not present limitations regarding equilibrium, i.e., the active component did not exhibit saturation or equilibrium line below 1 (or $100 \%$ release): the worst case scenario for all different $\mathrm{pH}$ values was $95-99 \%$ release. Due to this characteristic, the parameter $C_{\infty}$ of all equations derived from the rate law was not used to predict the concentration at equilibrium, but was set as unity instead. For those cases where equilibrium is achieved, this parameter cannot be 
Table 4

Ascorbic acid release at pH 5.4: Kinetic parameters and deviations calculated for the Rate Law equations and model PM2.

\begin{tabular}{|c|c|c|c|c|c|c|c|c|c|}
\hline \multirow[t]{2}{*}{ Model } & \multicolumn{6}{|c|}{ Parameters } & \multirow[t]{2}{*}{$\mathrm{R}^{2}$} & \multirow[t]{2}{*}{ AARD (\%) } & \multirow[t]{2}{*}{ RMSE } \\
\hline & \multicolumn{6}{|l|}{$\mathrm{k}$} & & & \\
\hline $0^{\text {th }}$ order & \multicolumn{6}{|c|}{$0.00449 \pm 0.00034$} & 0.7387 & 27.78 & 0.15 \\
\hline $1^{\text {st }}$ order & \multicolumn{6}{|c|}{$0.00921 \pm 0.00098$} & 0.8821 & 18.58 & 0.10 \\
\hline \multirow[t]{2}{*}{$2^{\text {nd }}$ order } & \multicolumn{6}{|c|}{$0.01667 \pm 0.00248$} & 0.8828 & 15.00 & 0.10 \\
\hline & $\mathbf{a}$ & $w_{1}$ & $\mathbf{k}_{1}$ & b & $\mathbf{w}_{2}$ & $\mathbf{k}_{2}$ & & & \\
\hline \multirow[t]{2}{*}{ PM2 } & $\begin{array}{l}0.4995 \\
\pm\end{array}$ & $\begin{array}{c}21.03 \\
\pm\end{array}$ & $\begin{array}{l}0.9815 \\
\pm\end{array}$ & $\begin{array}{l}0.4596 \\
\pm\end{array}$ & $\begin{array}{c}178.6 \\
\pm\end{array}$ & $\begin{array}{l}6.003 \\
\pm\end{array}$ & 0.9939 & 3.50 & 0.02 \\
\hline & 0.0446 & 4.48 & 0.3264 & 0.0226 & 4.6 & 0.892 & & & \\
\hline
\end{tabular}

For all Rate Law equations $\mathrm{C}_{\infty}$ was set as 1 (100\% release).

Table 5

Ascorbic acid release at pH 7.4: Kinetic parameters and deviations calculated for the Rate Law equations and model PM2.

\begin{tabular}{|c|c|c|c|c|c|c|c|c|c|}
\hline \multirow[t]{2}{*}{ Model } & \multicolumn{6}{|l|}{ Parameters } & \multirow[t]{2}{*}{$\mathrm{R}^{2}$} & \multirow[t]{2}{*}{ AARD (\%) } & \multirow[t]{2}{*}{ RMSE } \\
\hline & $\mathrm{k}$ & & & & & & & & \\
\hline 0th order & $0.00349 \pm 0.00016$ & & & & & & 0.8961 & 22.44 & 0.10 \\
\hline $1^{\text {st }}$ order & $0.00646 \pm 0.00054$ & & & & & & 0.9177 & 23.33 & 0.09 \\
\hline \multirow[t]{2}{*}{$2^{\text {nd }}$ order } & $0.01093 \pm 0.00165$ & & & & & & 0.8619 & 17.73 & 0.11 \\
\hline & $\mathbf{a}$ & $w_{1}$ & $\mathbf{k}_{1}$ & $\mathbf{b}$ & $\mathbf{w}_{2}$ & $\mathbf{k}_{2}$ & & & \\
\hline PM2 & $0.4047 \pm 0.0333$ & $24.44 \pm 6.16$ & $0.5911 \pm 0.0660$ & $0.5832 \pm 0.0345$ & $216.1 \pm 8.4$ & $3.763 \pm 0.412$ & 0.9943 & 1.78 & 0.02 \\
\hline
\end{tabular}

For all Rate Law equations $\mathrm{C}_{\infty}$ was set as 1 (100\% release).

Table 6

Ascorbic acid release at pH 9.6: Kinetic parameters and deviations calculated for the Rate Law equations and model PM2.

\begin{tabular}{|c|c|c|c|c|c|c|c|c|c|}
\hline \multirow[t]{2}{*}{ Model } & \multicolumn{6}{|l|}{ Parameters } & \multirow[t]{2}{*}{$\mathrm{R}^{2}$} & \multirow[t]{2}{*}{ AARD (\%) } & \multirow[t]{2}{*}{ RMSE } \\
\hline & $\mathrm{k}$ & & & & & & & & \\
\hline $0^{\text {th }}$ order & $0.00418 \pm 0.00033$ & & & & & & 0.7221 & 28.59 & 0.14 \\
\hline $1^{\text {st }}$ order & $0.00782 \pm 0.00097$ & & & & & & 0.8157 & 23.54 & 0.12 \\
\hline \multirow[t]{2}{*}{$2^{\text {nd }}$ order } & $0.01365 \pm 0.00227$ & & & & & & 0.8295 & 18.21 & 0.11 \\
\hline & $\mathbf{a}$ & $\mathrm{w}_{1}$ & $\mathbf{k}_{1}$ & $\mathbf{b}$ & $\mathrm{w}_{2}$ & $\mathbf{k}_{2}$ & & & \\
\hline PM2 & $0.4259 \pm 0.0070$ & $16.65 \pm 0.75$ & $1.606 \pm 0.234$ & $0.7122 \pm 0.1267$ & $216.7 \pm 16.8$ & $4.384 \pm 0.553$ & 0.9960 & 2.13 & 0.02 \\
\hline
\end{tabular}

For all Rate Law equations $\mathrm{C}_{\infty}$ was set as 1 (100\% release).

neglected in the mathematical estimation.

In order to mathematically describe the AA release of sample S8 at different $\mathrm{pH}$ values, five different models were tested as predictors, as showed in the Material and Methods section. Rate law models were fitted to the release data obtained at all $\mathrm{pH}$ conditions tested, while PM2 was applied only for those trials were a two-step release was identified (pH 5.4, 7.4 and 9.6 trials, Fig. 6).

As six parameters are unknown in model PM2, it cannot be directly applied in conventional parameter estimation. However, a two-step approach was successfully used to fit this model to the experimental data by following some conditions: i) the experimenter must choose

Table 7

Ascorbic acid release at $\mathrm{pH}$ 12.0: Kinetic parameters and deviations calculated from the Rate Law and the models proposed.

\begin{tabular}{lllll}
\hline Model & $\mathrm{k}$ & $\mathrm{R}^{2}$ & AARD (\%) & RMSE \\
\hline $0^{\text {th }}$ order & $0.01035 \pm 0.00177$ & 0.0696 & 37.40 & 0.30 \\
$1^{\text {st }}$ order & $0.03802 \pm 0.00728$ & 0.8520 & 14.19 & 0.12 \\
$2^{\text {nd }}$ order & $0.08312 \pm 0.01331$ & 0.9568 & 7.76 & 0.07 \\
\hline
\end{tabular}

For all equations $\mathrm{C}_{\infty}$ was set as $1(100 \%$ release). from the whole data set only those data that represent a first "regular exponential curve" and then fit them in PM1 using appropriate initial guesses for the three parameters; ii) using the whole data set, model PM2 can be used by substituting parameters $a, w_{1}$ and $k_{1}$ with the values found in step $i$. Although some obvious deviations may occur in the attempt to find the exact values of all parameters, these errors were considered low and proportionally comparable to those obtained based on the rate law. While avoiding the need of implementing complex algorithms in the parameter estimation step, this approach allowed using the same optimization method to the rate law-derived equations.

Model PM1 was not used to describe the whole data set since it is intended to predict well defined "regular" kinetic curves, i.e., the curve must have enough data points and its shape must be exponential or sigmoidal-like, as verified using external data (data not shown). As this model did not result in good predictions for our data, it was used only to predict parameters of PM2, as previously mentioned. Tables 3-7 show the kinetic parameters obtained for each model and the associated deviations.

As expected, for trials were a linear trend was observed $(\mathrm{pH} 1.1$ and 2.2, Fig. $5 \mathrm{~A}$ and $\mathrm{B}$ ), the $0^{\text {th }}$ order rate law equation presented the best prediction and the lower deviation. Very good correlations were observed for PM2, which showed $\mathrm{R}^{2}$ higher than 0.99 in all cases where 
applied. The 2nd order rate law equation was the mathematical model that best described the experimental data related to $\mathrm{pH} 12.0$ (Fig. 6C). Although the curve shape demonstrates a possible two-step release, there were not enough data to allow a proper application of model PM2.

Taking into account the best model fitting for different pHs, in general it was possible to obtain good correlations, as suggested by the $\mathrm{R}^{2}$ (0.94-0.99), AARD (1.78-15.36\%) and RMSE (0.02-0.09) values. The highest deviation related to $\mathrm{pH} 2.2$ occurs due to a similar tendency to the two-step release at $15-30 \mathrm{~min}$, when the data drift away from a linear trend, a characteristic of the $0^{\text {th }}$ order model. PM2 did not present a good fit to the data at $\mathrm{pH} 12.0$ due to the dearth of experimental data points in the region of interest.

\section{Conclusions}

Ascorbic acid microcapsules produced by complex coacervation using gum arabic and gelatin as wall materials have shown a good encapsulation efficiency, the wall material concentration and core percentage having a strong influence on the results. Solubility and hygroscopicity were low and the thermal stability of the active material improved significantly with the microencapsulation process. A slower release of AA was obtained at $\mathrm{pH}$ close to neutrality. The mathematical models applied showed good to excellent predictions of the release rate, being able to describe the release of AA from the microcapsules over different pHs. These results, together with the small mean diameter, render the microencapsulated AA thermo-stable and suitable for the food industry, especially when heat treatments are involved, as in the production of emulsified sausages.

\section{Acknowledgements}

The authors would like to thank CAPES (Coordination for the Improvement of Higher Education Personnel) - for the financial support.

\section{Appendix A. Supplementary data}

Supplementary data related to this article can be found at https:// doi.org/10.1016/j.foodhyd.2018.07.043.

\section{References}

Abbas, S., Wei, C. Da, Hayat, K., \& Xiaoming, Z. (2012). Ascorbic Acid: Microencapsulation techniques and trends - a review. Food Reviews International, 28, 343-374. (June 2012) https://doi.org/10.1080/87559129.2011.635390.

Alvim, I. D., \& Grosso, C. R. F. (2010). Microparticles obtained by complex coacervation: Influence of the type of reticulation and the drying process on the release of the core material. Ciência E Tecnologia de Alimentos, 30(4), 1069-1076. https://doi.org/10. 1590/S0101-20612010000400036.

Alvim, I. D., Souza, F. D. S., Koury, I. P., Jurt, T., \& Dantas, B. F. H. (2013). Use of the spray chilling method to deliver hydrophobic components: Physical characterization of microparticles. Ciência E Tecnologia de Alimentos, 33, 34-39. https://doi.org/10. 1590/S0101-20612013000500006.

Alvim, I. D., Stein, M. A., Koury, I. P., Dantas, F. B. H., \& Cruz, C. L.de C. V. (2016). Comparison between the spray drying and spray chilling microparticles contain ascorbic acid in a baked product application. Lebensmittel-Wissenschaft und -TechnologieFood Science and Technology, 65, 689-694. https://doi.org/10.1016/j.lwt.2015.08. 049.

Anvari, M., \& Chung, D. (2016). Dynamic rheological and structural characterization of fish gelatin - gum Arabic coacervate gels cross-linked by tannic acid. Food Hydrocolloids, 60, 516-524. https://doi.org/10.1016/j.foodhyd.2016.04.028.

AOAC International (2010). Official methods of analysis of AOAC International (18th ed.). Gaithersburg, USA: The Association (Official Method 967.21).

Belšćak-Cvitanović, A., Stojanović, R., Manojlović, V., Komes, D., Cindrić, I. J., Nedović, V., et al. (2011). Encapsulation of polyphenolic antioxidants from medicinal plant extracts in alginate-chitosan system enhanced with ascorbic acid by electrostatic extrusion. Food Research International, 44(4), 1094-1101. https://doi.org/10.1016/j. foodres.2011.03.030.

Benassi, M. T., \& Antunes, A. J. (1988). A comparison of metaphosphoric and oxalic acids as extractant solutions for the determination of vitamin $\mathrm{C}$ in selected vegetables. Arquivos de Biologia E Tecnologia, 31(4), 507-513.
Cai, Y. Z., \& Corke, H. (2000). Production and properties of 2,3-butanediol. Journal of Sensory and Nutritive Qualities of Food, 65(3600), 1248-1252.

Cano-Chauca, M., Stringheta, P. C., Ramos, A. M., \& Cal-Vidal, J. (2005). Effect of the carriers on the microstructure of mango powder obtained by spray drying and its functional characterization. Innovative Food Science \& Emerging Technologies, 6(4), 420-428. https://doi.org/10.1016/j.ifset.2005.05.003.

Comunian, T. A., Abbaspourrad, A., Favaro-Trindade, C. S., \& Weitz, D. A. (2014). Fabrication of solid lipid microcapsules containing ascorbic acid using a microfluidic technique. Food Chemistry, 152, 271-275. https://doi.org/10.1016/j.foodchem.2013. 11.149.

Comunian, T. A., \& Favaro-Trindade, C. S. (2016). Microencapsulation using biopolymers as an alternative to produce food enhanced with phytosterols and omega-3 fatty acids: A review. Food Hydrocolloids, 61, 442-457. https://doi.org/10.1016/j.foodhyd. 2016.06.003.

Comunian, T. A., Thomazini, M., Alves, A. J. G., de Matos Junior, F. E., de Carvalho Balieiro, J. C., \& Favaro-Trindade, C. S. (2013). Microencapsulation of ascorbic acid by complex coacervation: Protection and controlled release. Food Research International, 52(1), 373-379. https://doi.org/10.1016/j.foodres.2013.03.028.

Desai, K. G. H., \& Park, H. J. (2005). Encapsulation of vitamin C in tripolyphosphate cross-linked chitosan microspheres by spray drying. Journal of Microencapsulation, 22(2), 179-192. https://doi.org/10.1080/02652040400026533.

Dong, Z., Ma, Y., Hayat, K., Jia, C., Xia, S., \& Zhang, X. (2011). Morphology and release profile of microcapsules encapsulating peppermint oil by complex coacervation. Journal of Food Engineering, 104(3), 455-460. https://doi.org/10.1016/j.jfoodeng. 2011.01.011.

Doublier, J. L., Garnier, C., Renard, D., \& Sanchez, C. (2000). Protein-polysaccharide interactions. Current Opinion in Colloid \& Interface Science, 5(3-4), 202-214. https:// doi.org/10.1016/S1359-0294(00)00054-6.

Favaro-trindade, C. S., Pinho, S. C. De, Miguel, A. M. R. D. O., Garcia, A. E., Sarantópoulos, C. I. G. L., Jardim, D. C. P., ... Pinho, S. C. De. (2008). Revisão: Microencapsulação de ingredientes alimentícios. Brazilian Journal of Food Technology, 11, 103-112. https://doi.org/10.18406/2316-1817v1n32009223.

Fennema, O. R., Damodaran, S., \& Parkin, K. L. (2010). Fennema's food chemistry (Arthemed, Ed.)(4th ed.). (Porto Alegre).

Fereidoon Shahidi, \& Xiao-Qing Han (1993). Encapsulation of food ingredients. Critical Reviews in Food Science and Nutrition, 33(6), 501-547. https://doi.org/10.1021/bk1995-0590.ch003.

Gharsallaoui, A., Roudaut, G., Chambin, O., Voilley, A., \& Saurel, R. (2007). Applications of spray-drying in microencapsulation of food ingredients: An overview. Food Research International, 40(9), 1107-1121. https://doi.org/10.1016/j.foodres.2007. 07.004.

Gibbs, B. F., Kermasha, S., Alli, I., \& Mulligan, C. N. (1999). Encapsulation in the food industry: A review. International Journal of Food Sciences \& Nutrition, 50, 213-224.

Jingyan, S., Yuwen, L., Zhiyong, W., \& Cunxin, W. (2013). Investigation of thermal decomposition of ascorbic acid by TG-FTIR and thermal kinetics analysis. Journal of Pharmaceutical and Biomedical Analysis, 77, 116-119. https://doi.org/10.1016/j.jpba. 2013.01.018.

Kumari, A., Yadav, S. K. S. C., \& Yadav, S. K. S. C. (2010). Biodegradable polymeric nanoparticles based drug delivery systems. Colloids and Surfaces B: Biointerfaces, 75(1), 1-18. https://doi.org/10.1016/j.colsurfb.2009.09.001.

Lakkis, J. M. (2007). Encapsulation and controlled release technologies in food systems. Blackwell Publishing (p. Cap.1, 1-12.).

Lamprecht, A., Schäfer, U. F., \& Lehr, C. M. (2000). Characterization of microcapsules by confocal laser scanning microscopy: Structure, capsule wall composition and encapsulation rate. European Journal of Pharmaceutics and Biopharmaceutics, 49(1), 1-9. https://doi.org/10.1016/S0939-6411(99)00063-6.

Lv, Y., Zhang, X., Zhang, H., Abbas, S., \& Karangwa, E. (2013). The study of pH-dependent complexation between gelatin and gum Arabic by morphology evolution and conformational transition. Food Hydrocolloids, 30(1), 323-332. https://doi.org/10.1016/ j.foodhyd.2012.06.007.

Matalanis, A., Jones, O. G., \& McClements, D. J. (2011). Structured biopolymer-based delivery systems for encapsulation, protection, and release of lipophilic compounds. Food Hydrocolloids, 25(8), 1865-1880. https://doi.org/10.1016/j.foodhyd.2011.04. 014.

Matos-Jr, F. E., Di Sabatino, M., Passerini, N., Favaro-Trindade, C. S., \& Albertini, B. (2015). Development and characterization of solid lipid microparticles loaded with ascorbic acid and produced by spray congealing. Food Research International, 67, 52-59. https://doi.org/10.1016/j.foodres.2014.11.002.

Mendanha, D. V., Molina Ortiz, S. E., Favaro-Trindade, C. S., Mauri, A., MonterreyQuintero, E. S., \& Thomazini, M. (2009). Microencapsulation of casein hydrolysate by complex coacervation with SPI/pectin. Food Research International, 42(8), 1099-1104. https://doi.org/10.1016/j.foodres.2009.05.007.

Nakagawa, K., Iwamoto, S., Nakajima, M., Shono, A., \& Satoh, K. (2004). Microchannel emulsification using gelatin and surfactant-free coacervate microencapsulation. Journal of Colloid and Interface Science, 278(1), 198-205. https://doi.org/10.1016/j. jcis. 2004.05.031.

Nori, M. P., Favaro-Trindade, C. S., Matias de Alencar, S., Thomazini, M., de Camargo Balieiro, J. C., \& Contreras Castillo, C. J. (2011). Microencapsulation of propolis extract by complex coacervation. Lebensmittel-Wissenschaft und -Technologie- Food Science and Technology, 44(2), 429-435. https://doi.org/10.1016/j.lwt.2010.09.010.

Pierucci, A. P. T. R., Andrade, L. R., Baptista, E. B., Volpato, N. M., \& Rocha-Leão, M. H. M. (2006). New microencapsulation system for ascorbic acid using pea protein concentrate as coat protector. Journal of Microencapsulation, 23(6), 654-662. https:// doi.org/10.1080/02652040600776523.

Prata, A. S., \& Grosso, C. R. F. (2015). Influence of the oil phase on the microencapsulation by complex coacervation. JAOCS, Journal of the American Oil Chemists' 
Society, 92(7), 1063-1072. https://doi.org/10.1007/s11746-015-2670-z.

Prata, A. S., Menut, C., Leydet, A., Trigo, J. R., \& Grosso, C. R. F. (2008). Encapsulation and release of a fluorescent probe, khusimyl dansylate, obtained from vetiver oil by complex coacervation. Flavour and Fragrance Journal, 23, 7-15. https://doi.org/10. 1002/ffj. 1845 .

Ribeiro, M. D. M., Arellano, D. B., \& Grosso, C. R. F. (2012). The effect of adding oleic acid in the production of stearic acid lipid microparticles with a hydrophilic core by a spray-cooling process. Food Research International, 47(1), 38-44. https://doi.org/10. 1016/j.foodres.2012.01.007.

Rocha-Selmi, G. A., Bozza, F. T., Thomazini, M., Bolini, H. M. A., \& Fávaro-Trindade, C. S. (2013a). Microencapsulation of aspartame by double emulsion followed by complex coacervation to provide protection and prolong sweetness. Food Chemistry, 139(1-4), 72-78. https://doi.org/10.1016/j.foodchem.2013.01.114.

Rocha-Selmi, G. A., Theodoro, A. C., Thomazini, M., Bolini, H. M. A., \& Favaro-Trindade, C. S. (2013b). Double emulsion stage prior to complex coacervation process for microencapsulation of sweetener sucralose. Journal of Food Engineering, 119(1), 28-32. https://doi.org/10.1016/j.jfoodeng.2013.05.002.

Rozman, B., \& Gašperlin, M. (2007). Stability of vitamins C and E in topical microemulsions for combined antioxidant therapy. Drug Delivery, 14(4), 235-245. https:// doi.org/10.1080/10717540601067786.

Rutz, J. K., Borges, C. D., Zambiazi, R. C., Crizel-Cardozo, M. M., Kuck, L. S., \& Noreña, C. P. Z. (2017). Microencapsulation of palm oil by complex coacervation for application in food systems. Food Chemistry, 220, 59-66. https://doi.org/10.1016/j.foodchem. 2016.09.194.

Rutz, J. K., Borges, C. D., Zambiazi, R. C., Da Rosa, C. G., \& Da Silva, M. M. (2016). Elaboration of microparticles of carotenoids from natural and synthetic sources for applications in food. Food Chemistry, 202, 324-333. https://doi.org/10.1016/j. foodchem.2016.01.140.

Santos, M. G., Bozza, F. T., Thomazini, M., \& Favaro-Trindade, C. S. (2015). Microencapsulation of xylitol by double emulsion followed by complex coacervation. Food Chemistry, 171, 32-39. https://doi.org/10.1016/j.foodchem.2014.08.093.

Sartori, T., Consoli, L., Hubinger, M. D., \& Menegalli, F. C. (2015). Ascorbic acid microencapsulation by spray chilling: Production and characterization. LebensmittelWissenschaft und -Technologie- Food Science and Technology, 63(1), 353-360. https:// doi.org/10.1016/j.lwt.2015.03.112

Silva, D. F., Favaro-Trindade, C. S., Rocha, G. A., \& Thomazini, M. (2012). Microencapsulation of lycopene by gelatin-pectin complex coacervation. Journal of Food Processing and Preservation, 36(2), 185-190. https://doi.org/10.1111/j.1745- 4549.2011.00575.x.

Thies, C. (1995). Complex coacervation. How to make microcapsules - lecture and laboratory manual.

Torini, L., Argillier, J. F., \& Zydowicz, N. (2005). Interfacial polycondensation encapsulation in miniemulsion. Macromolecules, 38(8), 3225-3236. https://doi.org/10. 1021/ma047808e.

Trindade, M. A., \& Grosso, C. R. F. (2000). The stability of ascorbic acid microencapsulated in granules of rice starch and in gum arabic. Journal of Microencapsulation, 17(2), 169-176. https://doi.org/10.1080/026520400288409.

Uddin, M. S., Hawlader, M. N., \& Zhu, H. J. (2001). Microencapsulation of ascorbic acid: Effect of process variables on product characteristics. Journal of Microencapsulation, 18(2), 199-209. https://doi.org/10.1080/02652040010000352.

Yang, Z., Peng, Z., Li, J., Li, S., Kong, L., Li, P., et al. (2014). Development and evaluation of novel flavour microcapsules containing vanilla oil using complex coacervation approach. Food Chemistry, 145, 272-277. https://doi.org/10.1016/j.foodchem.2013. 08.074.

Zuanon, L. A. C., Malacrida, C. R., \& Telis, V. R. N. (2013). Production of turmeric oleoresin microcapsules by complex coacervation with gelatin-gum Arabic. Journal of Food Process Engineering, 36(3), 364-373. https://doi.org/10.1111/jfpe.12003.

\section{Further reading}

García-Saldaña, J. S., Campas-Baypoli, O. N., López-Cervantes, J., Sánchez-Machado, D. I., Cantú-Soto, E. U., \& Rodríguez-Ramírez, R. (2016). Microencapsulation of sulforaphane from broccoli seed extracts by gelatin/gum Arabic and gelatin/pectin complexes. Food Chemistry, 201, 94-100. https://doi.org/10.1016/j.foodchem.2016. 01.087.

de Souza, V. B., Thomazini, M., Echalar Barrientos, M. A., Nalin, C. M., Ferro-Furtado, R., Genovese, M. I., et al. (2018). Functional properties and encapsulation of a proanthocyanidin-rich cinnamon extract ( Cinnamomum zeylanicum ) by complex coacervation using gelatin and different polysaccharides. Food Hydrocolloids, 77, 297-306. https://doi.org/10.1016/j.foodhyd.2017.09.040. 